OPEN ACCESS

Edited by:

Yue Hou,

Northeastern University, China

Reviewed by:

Jun Zhang,

The University of Texas Health Science

Center at San Antonio, United States

Feilin Liu,

Mayo Clinic Florida, United States

${ }^{*}$ Correspondence:

Na Song

sarah_song1986@163.com

Haijun Wang

wnavy200299@163.com

Specialty section:

This article was submitted to Pharmacology of Anti-Cancer Drugs,

a section of the journal

Frontiers in Oncology

Received: 29 January 2021 Accepted: 24 March 2021

Published: 12 April 2021

Citation:

Wang $H$, Zhang $K$, Liu J, Yang J, Tian Y, Yang C, Li Y, Shao M, Su W and Song N (2021) Curcumin

Regulates Cancer Progression: Focus on ncRNAs and Molecular

Signaling Pathways.

Front. Oncol. 11:660712.

doi: 10.3389/fonc.2021.660712

\section{Curcumin Regulates Cancer Progression: Focus on ncRNAs and Molecular Signaling Pathways}

\author{
Haijun Wang ${ }^{1,2 *}$, Ke Zhang ${ }^{2}$, Jia Liu ${ }^{2}$, Jie Yang ${ }^{2}$, Yidan Tian ${ }^{2}$, Chen Yang ${ }^{2}$, Yushan Li $^{2}$, \\ Minglong Shao ${ }^{3}$, Wei Su ${ }^{1}$ and $\mathrm{Na} \mathrm{Song}^{2,4 *}$ \\ ${ }^{1}$ Department of Pathology, Key Laboratory of Clinical Molecular Pathology, The First Affiliated Hospital of Xinxiang Medical \\ University, Xinxiang, China, ${ }^{2}$ School of Basic Medical Sciences, Xinxiang Medical University, Xinxiang, China, ${ }^{3}$ Department of \\ Mental Health, The Second Affiliated Hospital of Xinxiang Medical University, Xinxiang, China, ${ }^{4}$ Institute of Precision \\ Medicine, Xinxiang Medical University, Xinxiang, China
}

Curcumin [(1E,6E) -1,7-bis(4-hydroxy-3-methoxyphenyl) hepta-1,6-diene-3,5- dione] is a natural polyphenol derived from the rhizome of the turmeric plant Curcuma longa. Accumulated evidences have presented curcumin's function in terms of antiinflammatory, antioxidant properties, and especially anti-tumor activities. Studies demonstrated that curcumin could exert anti-tumor activity via multiple biological signaling pathways, such as PI3K/Akt, JAK/STAT, MAPK, Wnt/ $\beta$-catenin, p53, NF-кB and apoptosis related signaling pathways. Moreover, Curcumin can inhibit tumor proliferation, angiogenesis, epithelial-mesenchymal transition (EMT), invasion and metastasis by regulating tumor related non-coding RNA (ncRNA) expression. In this review, we summarized the roles of curcumin in regulating signaling pathways and ncRNAs in different kinds of cancers. We also discussed the regulatory effect of curcumin through inhibiting carcinogenic miRNA and up regulating tumor suppressive miRNA. Furthermore, we aim to illustrate the cross regulatory relationship between ncRNA and signaling pathways, further to get a better understanding of the anti-tumor mechanism of curcumin, thus lay a theoretical foundation for the clinical application of curcumin in the future.

Keywords: curcumin, cancer, ncRNA, miRNA, signaling pathway, review

\section{INTRODUCTION}

Malignant tumor is a tremendous threat to human health with high heterogeneity. Most cancer retain untreatable although the understanding of cancer on a molecular level has been improved in the past years. According to the latest data released by World Health Organization (WHO), the number of deaths due to malignant tumors is still increasing every year (1). In exploring the way to treat cancer, scientists have been constantly finding and developing new drugs to treat cancer, including chemotherapy, radiotherapy, targeted drugs, and immunotherapy, and so on. Accumulated studies have shown that some natural compounds have a good effect on antitumor therapy, which provides us an alternative way to treat and manage cancer. 
Curcumin [(1E,6E)-1,7-bis(4-hydroxy-3-methoxyphenyl) hepta-1,6-diene-3,5-dione], an active component extracted from the rhizomes of Curcuma longa Linn (2), presents some favorable results in terms of anti-proliferation, anti-inflammation, anti-angiogenesis and anti-oxidation (3-8). Curcumin represents a promising phytochemicals in the field of anticancer to be used alone or combined with other drugs, which can affects multiple signaling pathways and molecular targets involved in cancer pathogenesis including NF-kB, MAPK, PTEN, p53, and ncRNA network (9).

A non-coding RNA (ncRNA) is a functional RNA molecule that is transcribed from DNA but not translated into proteins, which include microRNA (miRNA), small interfering RNA (siRNA), PIWI-interacting RNAs (piRNAs) and long noncoding RNAs (lncRNAs) (10-13). More and more studies have demonstrated that ncRNA plays an epigenetic regulatory role in the anti-cancer effect of curcumin, involving with histone modification, DNA methyltransferases, and regulation of microRNA (miRNA) expressions (14-18).

Although there have been reviews and talk about the role of curcumin in anti-tumor, it is mainly through explaining the regulation of curcumin in anti-tumor on related signal pathways, such as proliferation, invasion/migration, autophagy, apoptosis and other pathways (19-23), but there is no the relationship between ncRNA and pathway was clarified. In this review, we provide insights into the vital role and the signal pathways of curcumin in anti-cancer, and focus on the molecular mechanism of curcumin via ncRNA in regulating tumor development.

\section{PI3K-AKT SIGNAL PATHWAY}

The PI3K/AKT pathway is one of the major intracellular signaling pathways which has diverse downstream effects on basic intracellular functions, including cell proliferation, growth, apoptosis, epithelial-mesenchymal transition(ETM), metabolism and motility (24-26). The aberrant activation of the signaling pathway is often closely related to the occurrence and development of human cancers (27).

Studies show that miRNA-203,206 and miRNA-192-5p are very important tumor-inhibiting ncNRA. In a variety of tumors, they can inhibit tumor proliferation, invasion, migration, EMT, angiogenesis, etc (28-34). Curcumin could inhibit the cell proliferation and induce apoptosis of non-small cell lung cancer (NSCLC) cells via up-regulating the expression of miRNA-206/miRNA-192-5p and suppressing the PI3K/AKT/ mTOR signaling pathway $(35,36)$. On the contrary, miR-206/ miRNA-192-5p inhibitors could reverse the above results, following with the mTOR and Akt phosphorylation levels increase, which could promote cancer cell migration and invasion. Furthermore, miR-206/miRNA-192-5p mimics can also enhance curcumin inhibitory effect $(37,38)$. Curcumin might be a very effective agent for the treatment of NSCLC.

The most common genetic alteration activating PI3K is the genetic ablation of the tumor suppressor phosphatase and tensin homolog (PTEN), a negative regulator of PI3K-AKT signaling (39). miR-21 is one of the most frequently observed abnormal
miRNAs in human cancers and is one of the first miRNAs described as oncogenic ncRNA (40-44). A large-scale miRNA analysis of 540 samples from six different types of solid tumors showed that miR-21 is the only up-regulated miRNA in all cancer types (45).

Curcumin can effectively repress the miR-21/PTEN/Akt molecular pathway to inhibit cell proliferation and induce apoptosis in gastric cancer cells. The p-Akt protein expression is negatively correlated with curcumin dose, with curcumin levels increase, PTEN expression increased and miR-21 levels decreased (46-48). Qiang et al.'s study showed that curcumin can play a synergistic role with other chemotherapy drugs. Curcumin could facilitate the apoptosis effect of PD98059, a potent and selective inhibitor of mitogen-activated protein kinase, via the miR-21/PTEN/Akt pathway (48). Diphenyl difluoroketone (EF24), curcumin analogue, function to enhance apoptosis by inhibiting miR-21 in DU145 human prostate cancer cells and B16 mouse melanoma cells (49).

Curcumin inhibits the proliferation of bladder cancer cells (50). Curcumin mediated the expression of miR-203 increase by inducing hypomethylation of miR-203 promoter. The target genes of miR-203, Akt2, Src, Jun, and Survivin, were repressed in mRNA and protein level, leading to proliferation decrease and apoptosis increase of bladder cancer cells.

Curcumin significantly enhanced the apoptosis of renal carcinoma Caki cells induced by dual PI3K/Akt and mTOR inhibitor NVP-BEZ235. Curcumin suppress Bcl-2 level and the stability of Mcl-1 protein with p53 dependent mode. It is noteworthy that NVP-BEZ235 alone has no effect on the death of human renal cell carcinoma Caki cells, but NVP-BEZ235 combined with curcumin contributed cell apoptosis significantly with Bcl-2 and Mcl-1 reduction (51).

\section{JAK-STAT SIGNAL PATHWAY}

Constitutive activation of the Janus kinase/signal transducers and activators of transcription (JAK/STAT) pathway was first recognized as being related with malignancy in the 1990's (52). JAK-STAT pathways can be activated and employed by diverse cytokines, growth factors, and related molecules, that in turn phosphorylates their targets STATs $(53,54)$. Activated STATs, as the form of dimerization, are translocated into the nucleus and initiated the gene transcription.

The effects of JAK/STAT signaling on tumor cell survival, proliferation and invasion have made the JAK/STAT pathway a hotspot target for tumor targeted therapy and drug development $(55,56)$. The expression of miR-99a has been studied in many human cancers. It has been reported to be down-regulated in several types of cancer, including non-small cell lung cancer (NSCLC), liver cancer, bladder cancer, etc (57-59). These findings indicate that miR-99a is widely down-regulated in human cancers, indicating the potential role of miR-99a as a tumor suppressor.

Curcumin can inhibit the proliferation, migration, invasion and promote apoptosis of retinoblastoma cells, which function 
through up-regulating the miR-99a expression and then inhibiting JAK/STAT signaling pathway (60). In addition, curcumin can suppress the cell proliferation by downregulations of cyclinD1 and up-regulations of p21 expression. In one of studies showed that curcumin could reduce the antiapoptotic protein $\mathrm{Bcl}-2$, enhance the pro-apoptotic protein Bax and cleaved-caspase-3/9 expression level, ultimately promoted the apoptosis of retinoblastoma cells. Furthermore, curcumin can synergistically enhance the anti-tumor activity of cisplatin on papillary thyroid cancer (PTC) cells and tumor stem cell like cells by inhibiting the activity of STAT3, suggesting that curcumin combined with chemotherapy drugs may play a better therapeutic effect via JAK/STAT signaling pathway (61).

\section{WNT/B-CATENIN SIGNAL PATHWAY}

Wnt/ $\beta$-catenin signaling pathway, also called the canonical Wnt signaling pathway, is a highly conserved pathway in evolution. Activation of Wnt pathways can modulate cell proliferation, apoptosis, differentiation, migration, invasion, genetic stability, cell renewal. $\beta$-catenin is the core component of the cadherin complex and its stabilization is essential for the activation of $\mathrm{Wnt} / \beta$-catenin signaling. T-cell factor/lymph enhancer factor-1 (TCF/LEF1) is a transcription complex that mediates the transcription of genes triggered by classic Wnt pathway. When the Wnt pathway is activated, $\beta$-catenin can bind to the TCF/ LEF1 complex by translocating into the nucleus and bind to the target gene DNA to initiate the transcription of related genes, such as: cyclinD1, c-Myc, MMPs (62-66). Wnt/ $\beta$-catenin plays a vital role in tumor occurrence and treatment response.

The anti-cancer effect of curcumin is released by inhibiting the Wnt/ $\beta$-catenin pathway. In osteosarcoma, curcumin could promote the protein level of reversion-inducing cysteine-rich protein with kazal motifs (RECK) by reducing the expression of miR-21, further inhibited the Wnt pathway related proteins, such as: $\beta$-catenin, GSK-3 $\beta$ (67). Curcumin suppresses the NSCLC cell proliferation, migration, invasion and viability in a dose-dependent manner (68). Mechanistic analysis indicated that curcumin enhanced the expression level of miR-192-5p and decreased the expression of c-Myc. In addition, gene knockout miR-192-5p can rescue the curcumin-induced decrease of $\beta$-catenin, cyclin D1 and $\mathrm{c}-\mathrm{Myc}$ expression levels. These findings indicate that the upregulation of miR-192-5p, induced by curcumin, inhibits NSCLC cells with inactivation of $\mathrm{Wnt} / \beta$-catenin signaling pathway and down-regulation of c-Myc transcription. Dou et al. documented that curcumin suppresses colon cancer by inhibiting $\mathrm{Wnt} / \beta$ catenin pathway via down-regulating miR-130a, which may serve as a new target for colon cancer treatment (69).

As known, the lncRNA series (such as HOXA-AS2, HOTAIR and DANCR) function as oncogenes to promote cancer development and metastasis (70-72). Curcumin induced cell cycle arrest and apoptosis in hepatocellular carcinoma (HCC) by down-regulating lincROR which has been demonstrated to activate Wnt/ $\beta$-catenin signaling (73). Shao et al. documented that curcumin may suppress cell proliferation of HCC cell line
SMMC-7721, Huh-7, LO2 in a dose-dependent manner, the antiproliferation effect of curcumin was partly caused by $\mathrm{S}$ phase arrest. The apoptosis rate of SMMC-7721 and Huh-7 cells with curcumin treatment was significantly higher than that in DMSO treatment group. Moreover, curcumin inhibits cell viability through lincROR/ $\beta$-catenin regulatory pattern., Interestingly, the overexpression of lincROR partially reversed the inhibition of cell proliferation and rescue the inactivation of $\mathrm{Wnt} / \beta$-catenin in curcumin-treated HCC cells (74). Liu et al. also found that curcumin suppressed the proliferation and tumorigenicity through a ceRNA effect of miR145 and lncRNA-ROR in prostate cancer (75).

The cancer cells lose the characteristics of epithelial cells and acquire the mesenchymal phenotype, these changes are conducive to tumor cell invasion of surrounding tissues. The pathways associated with the EMT process have multiple signal cascades including the $\mathrm{Wnt} / \beta$-catenin pathway. The curcumin analog EF24 shows effective anti-tumor activity by preventing the cell cycle and inducing cell apoptosis in melanoma (76). EF24 could inactivate the Wnt pathway via up-regulating the expression of miR-33b, which was able to inhibit EMT in melanoma cell lines through downregulation of the mesenchymal markers, Vimentin and $\mathrm{N}$-cadherin. In addition, EF24 could decrease the phosphorylation of STAT3 and inhibit the HMGA2 expression, an oncological transcription factor, which promotes the proliferation of cancer cells and affect the progress of cell cycle in ovarian cancer cells and leukemia cells (77-79). In tamoxifenresistant breast cancer cells, Curcumin attenuates lncRNA H19induced epithelial-mesenchymal transition by the increase of $\mathrm{N}$ cadherin and the decrease of E-cadherin (80).

\section{MAPK SIGNAL PATHWAY}

The mitogen-activated protein kinase (MAPK) cascade is a key signaling pathway that regulates various cellular processes (such as proliferation, differentiation, transformation, apoptosis and stress response) under normal and pathological conditions (8184). Curcumin can inhibit proliferation and migration of human glioblastoma cells (85). miR-378 is considered to be a tumor suppressor miRNA, which has the ability to inhibit tumor cell proliferation, invasion and migration $(86,87)$. Li et al., proved that miR-378 is a downstream miRNA of glioblastoma multiforme, and it can enhance the inhibitory effect of curcumin on the growth of glioblastoma. Its inhibitory effect was enhanced in the stable U87 cells expressing miR-378 in vitro and in vivo compared with control cells. Moreover, it was found that curcumin can inhibit the expression of phosphorylated p38 at the protein level in U87 cells. miR-378 can counteract p38 inhibitory effect by increasing the phosphorylation of p38, further enhancing the sensitivity of cells to curcumin (85). Yu et al., showed that curcumin reduced the retinoblastoma cell viability and induced the apoptosis of Y79 cells through the activation of JNK and p38 MAPK pathways (88). Curcumin inhibits the growth and invasion of human monocytic leukemia SHI-1 cells in vivo by regulating MAPK and MMP signal transduction. The administration of curcumin significantly 
inhibited tumor growth, which showed that the tumor weight significantly decreased from $0.67 \mathrm{~g}$ (control) to $0.47 \mathrm{~g}(15 \mathrm{mg} / \mathrm{kg})$ and $0.35 \mathrm{~g}(30 \mathrm{mg} / \mathrm{kg})$. Curcumin inhibits the expression of PCNA in tumor tissues, and increases the degree of TUNEL and the staining of cleaved caspase-3. Curcumin treatment can be involved in the downregulation of NF- $\mathrm{KB}$ and ERK signals, and simultaneously activate p38 and JNK. And curcumin would attenuate the expression levels of MMP2, MMP9 and vimentin to affect the EMT process (89). Curcumin has also been shown to inhibit the growth of human A549 lung adenocarcinoma cells and induce apoptosis with a dose-dependent manner. Treatment of A549 cells by curcumin causes the increase of cytosolic cytochrome $\mathrm{c}$ and loss of mitochondrial membrane potential. Curcumin-induced apoptosis was accompanied by alterations in intracellular oxidative stress-related enzymes, including decreased reactive oxygen species (ROS), malondialdehyde and 4hydroxynonenal levels, increased superoxide dismutase (SOD), accompanied with the alteration of MAPK signaling pathway factors c-JNK, p38, ERK and apoptosis related protein, such as cleaved-caspase-3,9, Bcl-2, Bax, HSP70, and poly (ADP-ribose) polymerase (PARP) $(90,91)$. It may be owing to the biological activities of curcumin metabolites, which have cytotoxic effects represented by overhaul mutated DNA and remove free radicals, respectively $(92,93)$. Another study of NSCLC showed that curcumin strengthened the chemosensitivity of cisplatin the in A549 and H1703 cells via the downregulation of XRCC1. Breast cancer study revealed that the MAPK pathway mediated the down-regulation of EZH2, contributing to the anti-proliferative effects of curcumin against breast cancer (94). Taken together, curcumin exerts its anti-cancer role via MAPK signaling pathway in multiple types of cancer.

\section{P53 SIGNAL PATHWAY}

TP53 (p53), also described as the 'guardian of the genome', is the single most frequently altered gene in kinds of human cancers, the p53 mutations were observed in approximately 50\% of all invasive tumors (95-98). p53 is a tumor suppressor gene involved in a variety of cellular mechanisms, including DNA repair, apoptosis, and cell cycle arrest. p53 mutations in breast cancer have been associated with lower survival rates and resistance to conventional therapies. Curcumin interferes with the proliferation of breast cancer by up-regulating pro-apoptotic proteins (such as p53 and Bax) and down-regulating antiapoptotic proteins (such as MDM2 and Bcl-2). Studies showed that curcumin inhibited the proliferation of estrogen-receptorpositive MCF-7 human breast cancer cells from bisphenol A (BPA)-induced via modulating oncogenic miR-19 (99). Li et al., demonstrated that BPA exhibited estrogenic activity by increasing the proliferation of MCF-7 cells and triggering the cell transition from $\mathrm{G} 1$ to $\mathrm{S}$ phase. Curcumin inhibited the proliferation of BPA on MCF-7 cells. Meanwhile, BPA-induced upregulation of oncogenic miR-19a can be reversed by curcumin, including dysregulation of miR-19-related downstream proteins, such as PTEN, p-Akt, p-MDM2, p53, and proliferative nuclear antigen. These results indicate that curcumin can inhibit the proliferation of breast cancer mediated by BPA by regulating the miR-19/PTEN/AKT/p53 pathway (99).

It has been reported that curcumin leads to a markedly inhibition of cell growth, and promotes apoptosis in non-small cell lung cancer cells via p53-miR-192-5p/215-XIAP pathway (100). X-linked inhibitor of apoptosis (XIAP) is a member of the inhibitor of apoptosis family of proteins (IAP) and plays an important role in the process of resisting apoptosis $(101,102)$. More importantly, curcumin-induced increase in miR-192-5p/ 215 level was closely related to intracellular p53 status, only in wild-type cells (A549), while, curcumin does not cause an increase of miR-192-5p/215 in cells without p53 expression (H1299, p53-null). With miRBase, TargetScan, PicTar and miRDB target databases and luciferase assay, it was further discovered that XIAP is the direct target gene of miR-192-5p/ 215. Curcumin promotes cell apoptosis by increasing the level of miR-192-5p/215, which binds directly to resists apoptosis XIAP mRNA (100). Xu et al., demonstrated that curcumin mediates the sensitivity of bladder cancer cells to radiotherapy by activating p53. The combination of $10 \mu \mathrm{M}$ curcumin and radiation was more effective in reducing miR-1246 expression, cell viability and colony formation than curcumin or radiation alone. Inhibition of miR-1246 significantly reduces the cell viability and colony formation of T24 and HT-1376 cells. Luciferase reporter assay showed that miR-1246 can directly inhibit the expression of $\mathrm{p} 53$ gene. Finally, miR-1246 participates in the anti-cancer effects of curcumin and radiation by targeting to inhibiting the translation of p53 gene in bladder cancer cells (103).

Furthermore, mechanism studies have shown that curcumin can inhibit the growth of gastric cancer cells by down-regulating lncRNA H19 which was proved to be a oncomir $(104,105)$. Gao et al. proved that curcumin inhibits the proliferation of SGC7901 gastric cancer cells by repressing the expression of lncRNA H19 and enhancing the expression of p53. Meantime, curcumin can enhance the expression ratio of $\mathrm{Bax} / \mathrm{Bcl}-2$, both of them are downstream molecules of $\mathrm{p} 53$, thereby promoting cell apoptosis. Additionally, curcumin can also reduce the expression of oncogene c-Myc which indicate that curcumin inhibits the proliferation of gastric cancer cells by down-regulating the c-Myc/lncRNA H19 pathway (106).

\section{NF-KB SIGNAL PATHWAY}

$\mathrm{NF}-\kappa \mathrm{B}(\mathrm{NF}-\kappa \mathrm{B})$ is a transcription factor involved in a wide variety of biological activity. Growing evidence support its pivotal role in many steps of tumorigenesis and chemoresistance. Aberrant or constitutive NF-kB activation has been detected in many human malignancies (107-109). Suppression of the NF-kB signaling pathway has turned out to be a potential therapeutic approach for cancer treatment.

Studies showed that curcumin inhibits invasion and proliferation of cervical cancer cells via impairment of NF-kB and $\mathrm{Wnt} / \beta$-catenin pathways (110). Curcumin effectively 
inhibits oncogenic NF-kB signaling and restrains stemness features in liver cancer (111). Under hypoxic conditions, curcumin would attenuate the malignancy of pancreatic cancer cell invasion and EMT by interfering with tumor-stromal crosstalk via the ERK/NF- $\mathrm{KB}$ axis. Li et al., demonstrated that curcumin inhibits the activation and migration of pancreatic stellate cells (PSC), which play an important role in pancreatic cancer progression. Moreover, curcumin inhibits pancreatic cancer cell invasion, EMT and alters the expression of Ecadherin, vimentin, and MMP-9. Furthermore, curcumin can counteract the increased levels of p-ERK and p-NF- $\mathrm{BB}$ (112). Xiang et al., documented that curcumin also can repress the proliferation, migration and apoptosis by regulating the NF- $\kappa B$ signaling pathway in human colorectal carcinoma HCT-116 cells (113). In T47D breast cancer cells, curcumin treatment for $48 \mathrm{~h}$, prevented human autocrine growth hormone $(\mathrm{GH})$ signaling mediated NF-kB activation and miR-183-96-182 cluster stimulated epithelial mesenchymal transition (114). Animal study showed that curcumin suppressed the paclitaxelinduced NF-kB in breast cancer cells and strengthened the growth inhibitory effect of paclitaxel in a breast cancer nude mice mode. Compared with either drug alone, the combined treatment of paclitaxel and curcumin can significantly suppress cell proliferation and reduce tumor size, increase cell apoptosis, and reduce the expression of matrix metalloproteinase 9
(MMP9) (115). Studies demonstrated that curcumin inhibits both cyclo-oxygenase-2 enzyme (COX-2) and NF-kB. Therefore, it decreases binding of NF-kB to DNA and overpasses chemoresistance phenomenon in cancer cells (92, $93,116,117)$.The targeting of the NF- $\mathrm{kB}$ signaling by curcumin might be a treatment option for cancer.

\section{SUMMARY AND PROSPECT}

Natural compounds have been well known for their potential effect on preventing cancer progression and as complementary or standalone therapies for cancer treatment $(19,118,119)$. As a natural phenolic compound, curcumin is extracted from the dietary spice turmeric, showing an important significance in the adjuvant treatment of tumors with non-toxicity and tolerability (120-123). Curcumin participates in tumor control through multiple signaling pathways, including PI3K/Akt, JAK/STAT, MAPK, Wnt/ $\beta$ catenin, $\mathrm{p} 53, \mathrm{NF}-\mathrm{kB}$ and apoptosis related signaling pathways (Table 1). In addition, it is well known that ncRNA (including miRNA and lncRNA) plays an important role in the development of tumors. Curcumin regulates the expression of ncRNAs, which in turn affects the expression of related signaling pathway genes/ proteins, and ultimately inhibits tumor cell proliferation, promotes cell apoptosis, and enhances sensitivity to chemotherapy drugs

TABLE 1 | Curcumin modulates cellular signaling pathway and ncRNAs in cancers.

\begin{tabular}{|c|c|c|c|c|c|}
\hline Curcumin or analog & Signal Pathways & ncRNAs* & Downstream Targets & Cancer Type & Refs \\
\hline \multirow[t]{5}{*}{ Curcumin } & PI3K/Akt & $\operatorname{miR}-206(\uparrow)$ & p-Akt $(\downarrow), p-m T O R(\downarrow)$; & Non-small cell lung cancer & (23) \\
\hline & & miR-192-5p ( $\uparrow)$ & Caspase-3 ( $\uparrow)$, PI3K $(\downarrow)$, Akt $(\downarrow)$; & Non-small cell lung cancer & (24) \\
\hline & & $\operatorname{miR}-203(\uparrow)$ & Akt2 $(\downarrow)$, Src $(\downarrow)$, Jun $(\downarrow)$, Survivin $(\downarrow)$; & Bladder cancer & (30) \\
\hline & & $\operatorname{miR}-21(\downarrow)$ & $\operatorname{PTEN}(\uparrow), \operatorname{PI3K}(\downarrow)$, Akt $(\downarrow)$, p-Akt $(\downarrow)$; & Gastric cancer & $(27,28)$ \\
\hline & & & p21 ( $\uparrow)$, MMP2 $(\downarrow)$, MMP9 $(\downarrow)$ & Gastric cancer & \\
\hline Curcumin & JAK-STAT & $\operatorname{miR}-99 a(\uparrow)$ & $\begin{array}{l}\text { p-JAK1 }(\downarrow), \text { p-STAT1, } 3(\downarrow), \text { CyclinD1 }(\downarrow), \text { p21 }(\uparrow), \text { Bcl-2 }(\downarrow) \text {, Bax }(\uparrow), \\
\text { Cleaved-caspase-3,9 }(\uparrow) \text {, MMP2 }(\downarrow) \text {, RhoA }(\downarrow), \operatorname{ROCK} 1(\downarrow), \\
\text { Vimentin }(\downarrow) ;\end{array}$ & Retinoblastoma & $(37)$ \\
\hline Analog & Wnt/ $\beta$-catenin & miR-33b ( $)$ & $\begin{array}{l}\text { HMGA2 }(\downarrow) \text {, E-cadherin }(\uparrow) \text {, N-cadherin }(\downarrow) \text {, Vimentin }(\downarrow) \text {, p-STAT3 } \\
(\downarrow) ;\end{array}$ & Melanoma & (53) \\
\hline \multirow[t]{5}{*}{ Curcumin } & & miR-192-5p ( $\uparrow$ & Cyclin D1 $(\downarrow)$, c-Myc $(\downarrow), \beta$-catenin $(\downarrow)$; & Non-small cell lung cancer & $(45)$ \\
\hline & & $\operatorname{miR}-21(\downarrow)$ & $\begin{array}{l}\operatorname{Bcl}-2(\downarrow), \operatorname{Bax}(\uparrow), \operatorname{RECK}(\uparrow), \operatorname{MMP} 2(\downarrow), \text { c-Myc }(\downarrow), \beta \text {-catenin }(\downarrow) \text {, } \\
\operatorname{GSK}-3 \beta(\downarrow) ;\end{array}$ & Osteosarcoma & $(44)$ \\
\hline & & $\operatorname{miR}-130(\downarrow)$ & $\operatorname{Nkd2}(\downarrow), \beta$-catenin $(\downarrow)$, TCF4 $(\downarrow)$; & Colon cancer & $(46)$ \\
\hline & & $\operatorname{lincROR}(\downarrow)$ & $\beta$-catenin $(\downarrow)$, CD44 $(\downarrow)$, Oct3/4 $(\downarrow)$, CyclinD1 $(\downarrow)$, c-Myc $(\downarrow)$; & Hepatocellular carcinoma & $(51)$ \\
\hline & & 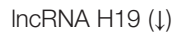 & E-cadherin $(\uparrow)$, N-cadherin $(\downarrow)$, Vimentin $(\downarrow)$; & Breast cancer & $(57)$ \\
\hline \multirow[t]{6}{*}{ Curcumin } & MAPK & $\operatorname{miR}-378(\uparrow)$ & p-p38 ( $\uparrow)$ & Glioblastoma & (62) \\
\hline & & / & $\begin{array}{l}\text { p-JNK }(\uparrow) \text {, Cyclin D3 }(\downarrow), \text { CDK2,6 }(\downarrow), \text { p21 }(\uparrow), \text { p27 }(\uparrow) \text {, Cleaved- } \\
\text { caspase-3,9 }(\uparrow), p-p 38(\uparrow) ;\end{array}$ & Retinoblastoma & $(63)$ \\
\hline & & / & $\begin{array}{l}\text { p-JNK }(\uparrow), \text { p-p38 }(\uparrow), p-E R K 1,2(\downarrow), p-p 65(\downarrow), \text { MMP2 }(\downarrow), \text { MMP9 } \\
(\downarrow), \text { Vimentin }(\downarrow) ;\end{array}$ & Leukaemia & $(64)$ \\
\hline & & / & p-p38 ( $\uparrow)$, p-JNK $(\uparrow)$, Cleaved-caspase-3,9 $(\uparrow)$, Bcl-2 $(\downarrow)$, Bax $(\uparrow)$ & Non-small cell lung cancer & $(65)$ \\
\hline & & & HSP70 $(\downarrow)$ & Colon cancer & (66) \\
\hline & & & Cleaved-PARP $(\uparrow)$, ATF2 $(\uparrow), N F-\kappa B(\downarrow)$ & & \\
\hline \multirow[t]{4}{*}{ Curcumin } & p53 & $\operatorname{miR}-19(\downarrow)$ & p53 ( $\uparrow)$, p-MDM2 $(\downarrow)$, PCNA $(\downarrow)$, p-Akt $(\downarrow)$, PTEN $(\uparrow) ;$ & Breast cancer & $(74)$ \\
\hline & & $\operatorname{miR}-1246(\downarrow)$ & p53 ( $\uparrow$ & Bladder cancer & $(78)$ \\
\hline & & IncRNA H19 ( $\downarrow)$ & p53 $(\uparrow)$, Bcl-2 $(\downarrow), \operatorname{Bax}(\uparrow)$, c-Myc $(\downarrow) ;$ & Gastric cancer & (79) \\
\hline & & $\begin{array}{l}\operatorname{miR}-192-5 p(\uparrow) \\
\operatorname{miR}-215(\uparrow)\end{array}$ & $\begin{array}{l}\text { p53 }(\uparrow), \text { p21 }(\uparrow) \text {, Cleaved-PARP }(\uparrow) \text {, Cleaved-caspase-3 }(\uparrow), \text { XIAP } \\
(\uparrow) ;\end{array}$ & Non-small cell lung cancer & $(75)$ \\
\hline \multirow[t]{2}{*}{ Curcumin } & $\mathrm{NF}-\kappa \mathrm{B}$ & / & p-ERK $(\downarrow), p-N F-\kappa B(\downarrow)$, MMP9 $(\downarrow)$, Vimentin $(\downarrow)$; & Pancreatic cancer & (85) \\
\hline & & & $\begin{array}{l}\text { Fas }(\uparrow) \text {, FADD }(\uparrow) \text {, Cleaved-caspase-3,8 }(\uparrow) \text {, MMP-9 }(\downarrow) \text {, NF- } \kappa B(\downarrow) \text {, } \\
\text { E-cadherin }(\uparrow) \text {, claudin-3 }(\downarrow) \text {, }\end{array}$ & Colon cancer & $(86)$ \\
\hline
\end{tabular}

${ }^{*}$ ncRNAs expression altered under curcumin treatment. 


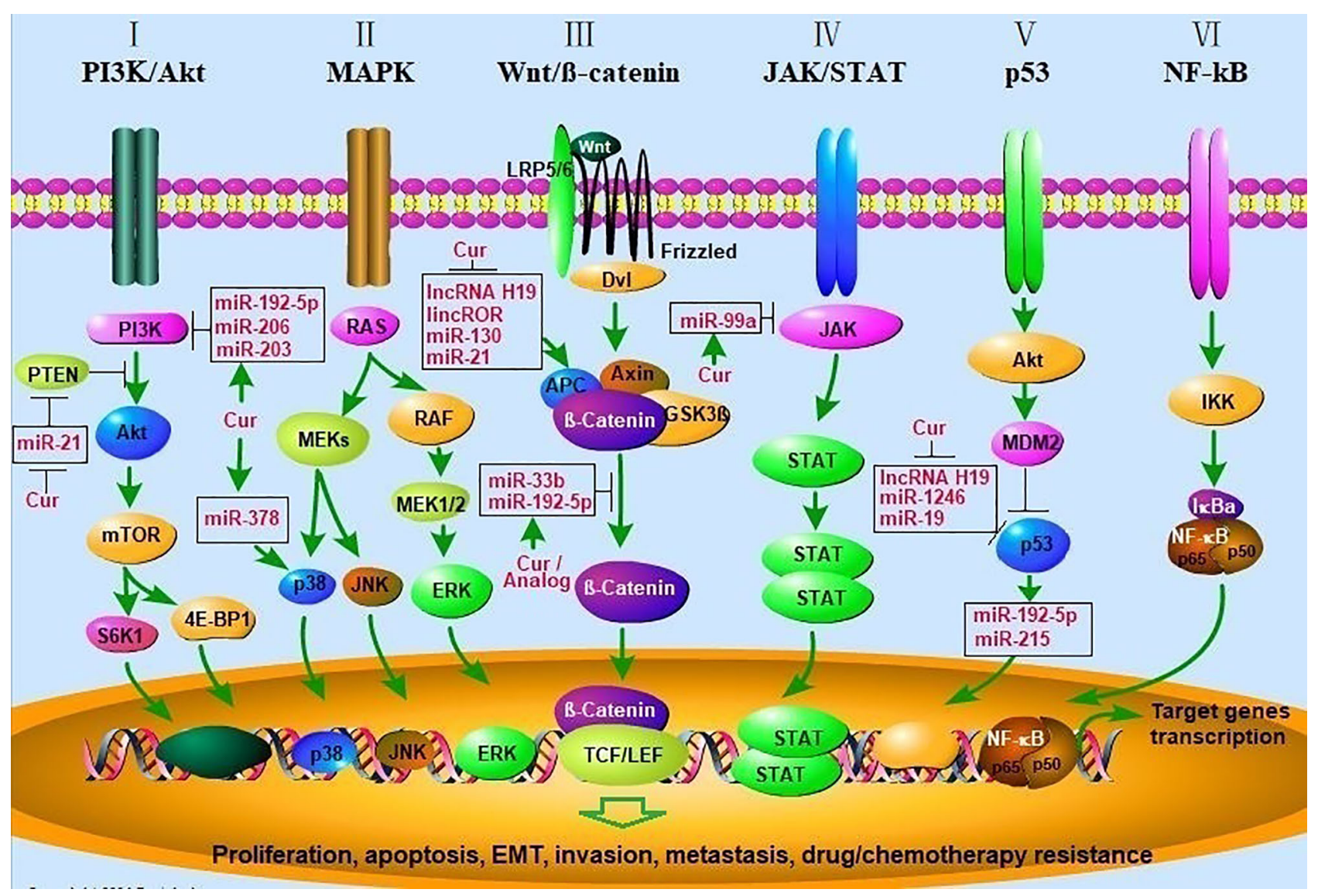

FIGURE 1 | Curcumin modulates cancer progression by regulating multiple signal transduction pathways. (I) Akt/PI3K/mTOR signaling pathway. PTEN inhibits the activation of Akt by PI3K, mTOR phosphorylates P70S6K1 (S6K1) and 4E-BP1 leading to activation of pathways involved in cell growth and survival. Curcumin inhibit the AKt/PI3K/mTOR pathway by enhancing the activity of PTEN via decreasing miR-21 and inhibiting the activity of Pl3K via upregulating miR-192-5p, miR-206, miR203; (II) MAPK signaling pathway. Signaling cascades leading to activation of the MEKs, which lead to activation of the ERK1/2, p38, and JNK cascades, and then initiate the gene transcription. Curcumin activated p38 MAPK via upregulating miR-378, leading to elevated p21/27, cleaved-caspase-3,9 expression, decreased Bcl-2, MMP2/9 expression. (III) Wnt/ $\beta$-catenin pathway. Wnt binds both Frizzled and LRP5/6 receptors to initiate the dissociation of the Axin/APC/GSK3 3 complex. $\beta$-catenin phosphorylation and then translocates to the nucleus to bind TCF/LEF co-transcription factors, which induces the Wnt-response gene transcription. Curcumin inhibits the Wnt/ $\beta$-catenin pathway by inhibiting IncRNA H19, lincROR, miR-130, 21 and upregulating miR-192-5p and miR-33b; (IV) JAK/STAT signaling. The pathway is activated by the binding of a ligand and then convey signals downstream STATs, whereas STATs are transcription factors that activate gene expression; (V) p53 signaling pathway. AKT-induced activation of MDM2, which can inhibit the antitumor activity of p53. Curcumin enhances the anti-tumor activity of p53 by inhibiting IncRNA H19, miR-1246, miR-19; (VI) NF-kB signaling pathway. Signaling cascade leads to the phosphorylation of IkB $\alpha$ resulting in degradation by the proteasome. This releases the NF-kB/p65/p50 complex and allows it to translocate to the nucleus for gene transcription. AKT, v-akt murine thymoma viral oncogene; PI3K, phosphatidylinositol 3-kinase; mTOR, mammalian target of rapamycin; PTEN, phosphatase and tensin homolog; MAPK, mitogen-activated protein kinase; MMP, matrix metalloprotinase), ERKs (extracellular regulated protein kinases), JNK (c-Jun N-terminal kinase; APC, adenomatous polyposis coli; Dvl, Disheveled; GSK3 $\beta$, glycogen synthase kinase 3B; LRP5/6, low density lipoprotein receptor-related protein 5/6; TCF/LEF, T-cell factor/lymphoid enhancer-binding factor; JAK/STAT, janus kinase/ signal transducers and activators of transcription; MDM2, murine double minute 2; NF-kB, nuclear factor kappa B; IKK, IкB kinase; IкBa, IkappaBa.

(Figure 1). These findings will help us better understand the molecular mechanism between curcumin and ncRNAs in antitumor, and the potentiality of clinical adjuvant treatment. Collectively, curcumin is a natural compound with potential drug value in adjuvant treatment of tumors.

\section{AUTHOR CONTRIBUTIONS}

All authors listed have made a substantial, direct, and intellectual contribution to the work, and approved it for publication.

\section{FUNDING}

This work was supported by National Natural Science Foundation of China (U1904133,81903688), Program for Young Key Teachers in Colleges and Universities in Henan Province (2020GGJS150), the Natural Science Foundation of Henan Province of China (212300410224), and Scientific Research Foundation of Xinxiang Medical University (XYBSKYZZ201512). This work was also supported by National Training Programs of Innovation and Entrepreneurship for Undergraduates (202010472011). 


\section{REFERENCES}

1. Bray F, Ferlay J, Soerjomataram I, Siegel RL, Torre LA, Jemal A. Global cancer statistics 2018: GLOBOCAN estimates of incidence and mortality worldwide for 36 cancers in 185 countries. CA Cancer J Clin (2018) 68:394424. doi: $10.3322 /$ caac. 21492

2. Zhang JY, Lin MT, Zhou MJ, Yi T, Tang YN, Tang SL, et al. Combinational Treatment of Curcumin and Quercetin against Gastric Cancer MGC-803 Cells in Vitro. Molecules (2015) 20:11524-34. doi: 10.3390/ molecules200611524

3. Zhao Y, Sun J, Dou W, Hu JH. Curcumin inhibits proliferation of interleukin-22-treated HaCaT cells. Int J Clin Exp Med (2015) 8:9580-4

4. Xu Y, Zhang J, Han J, Pan X, Cao Y, Guo H, et al. Curcumin inhibits tumor proliferation induced by neutrophil elastase through the upregulation of alpha1-antitrypsin in lung cancer. Mol Oncol (2012) 6:405-17. doi: 10.1016/ j.molonc.2012.03.005

5. Chen L, Zhan CZ, Wang T, You H, Yao R. Curcumin Inhibits the Proliferation, Migration, Invasion, and Apoptosis of Diffuse Large B-Cell Lymphoma Cell Line by Regulating MiR-21/VHL Axis. Yonsei Med J (2020) 61:20-9. doi: 10.3349/ymj.2020.61.1.20

6. Siriviriyakul $\mathrm{P}$, Chingchit $\mathrm{T}$, Klaikeaw N, Chayanupatkul M, Werawatganon D. Effects of curcumin on oxidative stress, inflammation and apoptosis in Larginine induced acute pancreatitis in mice. Heliyon (2019) 5:e02222. doi: 10.1016/j.heliyon.2019.e02222

7. Gaikwad D, Shewale R, Patil V, Mali D, Gaikwad U, Jadhav N. Enhancement in in vitro anti-angiogenesis activity and cytotoxicity in lung cancer cell by pectin-PVP based curcumin particulates. Int J Biol Macromol (2017) 104:656-64. doi: 10.1016/j.ijbiomac.2017.05.170

8. Yang L, Zheng Z, Qian C, Wu J, Liu Y, Guo S, et al. Curcuminfunctionalized silk biomaterials for anti-aging utility. J Colloid Interface Sci (2017) 496:66-77. doi: 10.1016/j.jcis.2017.01.115

9. Liu Y SH, Makabel B, Cui Q, Li J, Su C, Ashby CRJr, et al. The targeting of non-coding RNAs by curcumin: Facts and hopes for cancer therapy (Review). Oncol Rep (2019) 42:20-34. doi: 10.3892/or.2019.7148

10. Romano G, Veneziano D, Acunzo M, Croce CM. Small non-coding RNA and cancer. Carcinogenesis (2017) 38:485-91. doi: 10.1093/carcin/bgx026

11. Slack FJ, Chinnaiyan AM. The Role of Non-coding RNAs in Oncology. Cell (2019) 179:1033-55. doi: 10.1016/j.cell.2019.10.017

12. Czech B, Munafo M, Ciabrelli F, Eastwood EL, Fabry MH, Kneuss E, et al. piRNA-Guided Genome Defense: From Biogenesis to Silencing. Annu Rev Genet (2018) 52:131-57. doi: 10.1146/annurev-genet-120417-031441

13. Liu Y, Dou M, Song X, Dong Y, Liu S, Liu H, et al. The emerging role of the piRNA/piwi complex in cancer. Mol Cancer (2019) 18:123. doi: 10.1186/ s12943-019-1052-9

14. Wei JW, Huang K, Yang C, Kang CS. Non-coding RNAs as regulators in epigenetics (Review). Oncol Rep (2017) 37:3-9. doi: 10.3892/or.2016.5236

15. Mehta A, Dobersch S, Romero-Olmedo AJ, Barreto G. Epigenetics in lung cancer diagnosis and therapy. Cancer Metastasis Rev (2015) 34:229-41. doi: 10.1007/s10555-015-9563-3

16. Esteller M. Non-coding RNAs in human disease. Nat Rev Genet (2011) 12:861-74. doi: $10.1038 / \mathrm{nrg} 3074$

17. Stefanska B, MacEwan DJ. Epigenetics and pharmacology. Br J Pharmacol (2015) 172:2701-4. doi: 10.1111/bph.13136

18. Kaikkonen MU, Adelman K. Emerging Roles of Non-Coding RNA Transcription. Trends Biochem Sci (2018) 43:654-67. doi: 10.1016/ j.tibs.2018.06.002

19. Giordano A, Tommonaro G. Curcumin and Cancer. Nutrients (2019) 11:2376. doi: $10.3390 /$ nul1102376

20. Tomeh MA, Hadianamrei R, Zhao X. A Review of Curcumin and Its Derivatives as Anticancer Agents. Int J Mol Sci (2019) 20:1033. doi: 10.3390/ijms20051033

21. Shanmugam MK, Rane G, Kanchi MM, Arfuso F, Chinnathambi A, Zayed $\mathrm{ME}$, et al. The multifaceted role of curcumin in cancer prevention and treatment. Molecules (2015) 20:2728-69. doi: 10.3390/molecules20022728

22. Mbese Z, Khwaza V, Aderibigbe BA. Curcumin and Its Derivatives as Potential Therapeutic Agents in Prostate, Colon and Breast Cancers. Molecules (2019) 24:4386. doi: 10.3390/molecules 24234386
23. Baldi A, De Luca A, Maiorano P, D’Angelo C, Giordano A. Curcumin as an Anticancer Agent in Malignant Mesothelioma: A Review. Int J Mol Sci (2020) 21:1839. doi: 10.3390/ijms21051839

24. Noorolyai S, Shajari N, Baghbani E, Sadreddini S, Baradaran B. The relation between PI3K/AKT signalling pathway and cancer. Gene (2019) 698:120-8. doi: 10.1016/j.gene.2019.02.076

25. Xu W, Yang Z, Lu N. A new role for the PI3K/Akt signaling pathway in the epithelial-mesenchymal transition. Cell Adh Migr (2015) 9:317-24. doi: 10.1080/19336918.2015.1016686

26. Cheng J, Huang Y, Zhang X, Yu Y, Wu S, Jiao J, et al. TRIM21 and PHLDA3 negatively regulate the crosstalk between the PI3K/AKT pathway and PPP metabolism. Nat Commun (2020) 11:1880. doi: 10.1038/s41467-02015819-3

27. Fresno Vara JA, Casado E, de Castro J, Cejas P, Belda-Iniesta C, GonzalezBaron M. PI3K/Akt signalling pathway and cancer. Cancer Treat Rev (2004) 30:193-204. doi: 10.1016/j.ctrv.2003.07.007

28. Chao P, Yongheng F, Jin Z, Yu Z, Shiyong Y, Kunxing Y, et al. IncRNA HOTAIR knockdown suppresses gastric cancer cell biological activities. Food Sci Nutr (2021) 9:123-34. doi: 10.1002/fsn3.1970

29. Park YR, Seo SY, Kim SL, Zhu SM, Chun S, Oh JM, et al. MiRNA-206 suppresses PGE2-induced colorectal cancer cell proliferation, migration, and invasion by targetting TM4SF1. Biosci Rep (2018) 38:BSR20180664. doi: 10.1042/BSR20180664

30. Chen XF, Guo JF, Xu JF, Yin SH, Cao WL. MiRNA-206 inhibits proliferation of renal clear cell carcinoma by targeting ZEB2. Eur Rev Med Pharmacol Sci (2019) 23:7826-34. doi: 10.26355/eurrev_201909_18992

31. Yang N, Wang L, Liu J, Liu L, Huang J, Chen X, et al. MicroRNA-206 regulates the epithelial-mesenchymal transition and inhibits the invasion and metastasis of prostate cancer cells by targeting Annexin A2. Oncol Lett (2018) 15:8295-302. doi: 10.3892/ol.2018.8395

32. Liang Z, Bian X, Shim H. Downregulation of microRNA-206 promotes invasion and angiogenesis of triple negative breast cancer. Biochem Biophys Res Commun (2016) 477:461-6. doi: 10.1016/j.bbrc.2016.06.076

33. Sun C, Liu Z, Li S, Yang C, Xue R, Xi Y, et al. Down-regulation of c-Met and Bcl2 by microRNA-206, activates apoptosis, and inhibits tumor cell proliferation, migration and colony formation. Oncotarget (2015) 6:2553374. doi: 10.18632/oncotarget.4575

34. Yang L, Liang H, Wang Y, Gao S, Yin K, Liu Z, et al. MiRNA-203 suppresses tumor cell proliferation, migration and invasion by targeting Slug in gastric cancer. Protein Cell (2016) 7:383-7. doi: 10.1007/s13238-016-0259-4

35. Yan D, Dong Xda E, Chen X, Wang L, Lu C, Wang J, et al. MicroRNA-1/206 targets c-Met and inhibits rhabdomyosarcoma development. J Biol Chem (2009) 284:29596-604. doi: 10.1074/jbc.M109.020511

36. Zhang Y, He Y, Lu LL, Zhou ZY, Wan NB, Li GP, et al. miRNA-192-5p impacts the sensitivity of breast cancer cells to doxorubicin via targeting peptidylprolyl isomerase A. Kaohsiung J Med Sci (2019) 35:17-23. doi: 10.1002/kjm2.12004

37. Wang N, Feng T, Liu X, Liu Q. Curcumin inhibits migration and invasion of non-small cell lung cancer cells through up-regulation of miR-206 and suppression of PI3K/AKT/mTOR signaling pathway. Acta Pharm (2020) 70:399-409. doi: 10.2478/acph-2020-0029

38. Jin H, Qiao F, Wang Y, Xu Y, Shang Y. Curcumin inhibits cell proliferation and induces apoptosis of human non-small cell lung cancer cells through the upregulation of miR-192-5p and suppression of PI3K/Akt signaling pathway. Oncol Rep (2015) 34:2782-9. doi: 10.3892/or.2015.4258

39. Yin Y, Shen WH. PTEN: a new guardian of the genome. Oncogene (2008) 27:5443-53. doi: 10.1038/onc.2008.241

40. Qi R, Wang DT, Xing LF, Wu ZJ. miRNA-21 promotes gastric cancer growth by adjusting prostaglandin E2. Eur Rev Med Pharmacol Sci (2018) 22:1929-36. doi: 10.26355/eurrev_201804_14717

41. Markou A, Zavridou M, Lianidou ES. miRNA-21 as a novel therapeutic target in lung cancer. Lung Cancer (Auckl) (2016) 7:19-27. doi: 10.2147/ LCTT.S60341

42. Yang Q, Yu H, Yin Q, Hu X, Zhang C. lncRNA-NEF is downregulated in osteosarcoma and inhibits cancer cell migration and invasion by downregulating miRNA-21. Oncol Lett (2019) 17:5403-8. doi: 10.3892/ ol.2019.10276 
43. Wang Y, Zhang P, Yuan M, Li X. Overexpression of miRNA-21 Promotes the Proliferation and Invasion in Hepatocellular Carcinoma Cells via Suppressing SMAD7. Technol Cancer Res Treat (2019) 18:1533033819878686. doi: 10.1177/1533033819878686

44. Wang Y, Zhou S, Fan K, Jiang C. MicroRNA-21 and its impact on signaling pathways in cervical cancer. Oncol Lett (2019) 17:3066-70. doi: 10.3892/ ol.2019.10002

45. Volinia S, Calin GA, Liu CG, Ambs S, Cimmino A, Petrocca F, et al. A microRNA expression signature of human solid tumors defines cancer gene targets. Proc Natl Acad Sci USA (2006) 103:2257-61. doi: 10.1073/ pnas. 0510565103

46. Chen J, Xu T, Chen C. The critical roles of miR-21 in anti-cancer effects of curcumin. Ann Transl Med (2015) 3:330. doi: 10.3978/j.issn.23055839.2015.09.20

47. Liu W, Huang M, Zou Q, Lin W. Curcumin suppresses gastric cancer biological activity by regulation of miRNA-21: an in vitro study. Int J Clin Exp Pathol (2018) 11:5820-9.

48. Qiang Z, Meng L, Yi C, Yu L, Chen W, Sha W. Curcumin regulates the miR21/PTEN/Akt pathway and acts in synergy with PD98059 to induce apoptosis of human gastric cancer MGC-803 cells. J Int Med Res (2019) 47:1288-97. doi: 10.1177/0300060518822213

49. Yang CH, Yue J, Sims M, Pfeffer LM. The curcumin analog EF24 targets NFkappaB and miRNA-21, and has potent anticancer activity in vitro and in vivo. PloS One (2013) 8:e71130. doi: 10.1371/journal.pone.0071130

50. Saini S, Arora S, Majid S, Shahryari V, Chen Y, Deng G, et al. Curcumin modulates microRNA-203-mediated regulation of the Src-Akt axis in bladder cancer. Cancer Prev Res (Phila) (2011) 4:1698-709. doi: 10.1158/ 1940-6207.CAPR-11-0267

51. Seo BR, Min KJ, Cho IJ, Kim SC, Kwon TK. Curcumin significantly enhances dual PI3K/Akt and mTOR inhibitor NVP-BEZ235-induced apoptosis in human renal carcinoma Caki cells through down-regulation of p53dependent Bcl-2 expression and inhibition of Mcl-1 protein stability. PloS One (2014) 9:e95588. doi: 10.1371/journal.pone.0095588

52. Leonard WJ, O'Shea JJ. Jaks and STATs: biological implications. Annu Rev Immunol (1998) 16:293-322. doi: 10.1146/annurev.immunol.16.1.293

53. Rawlings JS, Rosler KM, Harrison DA. The JAK/STAT signaling pathway. J Cell Sci (2004) 117:1281-3. doi: 10.1242/jcs.00963

54. Harrison DA. The Jak/STAT pathway. Cold Spring Harb Perspect Biol (2012) 4:a011205. doi: 10.1101/cshperspect.a011205

55. Thomas SJ, Snowden JA, Zeidler MP, Danson SJ. The role of JAK/STAT signalling in the pathogenesis, prognosis and treatment of solid tumours. $\mathrm{BrJ}$ Cancer (2015) 113:365-71. doi: 10.1038/bjc.2015.233

56. Morris R, Kershaw NJ, Babon JJ. The molecular details of cytokine signaling via the JAK/STAT pathway. Protein Sci (2018) 27:1984-2009. doi: 10.1002/pro.3519

57. Yan HZ, Wang W, Du X, Jiang XD, Lin CY, Guo JL, et al. The expression and clinical significance of miRNA-99a and miRNA-224 in non-small cell lung cancer. Eur Rev Med Pharmacol Sci (2019) 23:1545-52. doi: 10.26355/ eurrev_201902_17113

58. Tao C, Sun H, Sang W, Li S. miRNA-99a inhibits cell invasion and migration in liver cancer by directly targeting HOXA1. Oncol Lett (2019) 17:5108-14. doi: 10.3892/ol.2019.10199

59. Wu D, Zhou Y, Pan H, Zhou J, Fan Y, Qu P. microRNA-99a inhibiting cell proliferation, migration and invasion by targeting fibroblast growth factor receptor 3 in bladder cancer. Oncol Lett (2014) 7:1219-24. doi: 10.3892/ ol.2014.1875

60. Li Y, Sun W, Han N, Zou Y, Yin D. Curcumin inhibits proliferation, migration, invasion and promotes apoptosis of retinoblastoma cell lines through modulation of miR-99a and JAK/STAT pathway. BMC Cancer (2018) 18:1230. doi: 10.1186/s12885-018-5130-y

61. Khan AQ, Ahmed EI, Elareer N, Fathima H, Prabhu KS, Siveen KS, et al. Curcumin-Mediated Apoptotic Cell Death in Papillary Thyroid Cancer and Cancer Stem-Like Cells through Targeting of the JAK/STAT3 Signaling Pathway. Int J Mol Sci (2020) 21:438. doi: 10.3390/ijms21020438

62. Pai SG, Carneiro BA, Mota JM, Costa R, Leite CA, Barroso-Sousa R, et al. Wnt/beta-catenin pathway: modulating anticancer immune response. J Hematol Oncol (2017) 10:101. doi: 10.1186/s13045-017-0471-6

63. Zhang $\mathrm{Y}$, Wang $\mathrm{X}$. Targeting the Wnt/beta-catenin signaling pathway in cancer. J Hematol Oncol (2020) 13:165. doi: 10.1186/s13045-020-00990-3
64. MacDonald BT, Tamai K, He X. Wnt/beta-catenin signaling: components, mechanisms, and diseases. Dev Cell (2009) 17:9-26. doi: 10.1016/ j.devcel.2009.06.016

65. Song N, Zhong J, Hu Q, Gu T, Yang B, Zhang J, et al. FGF18 Enhances Migration and the Epithelial-Mesenchymal Transition in Breast Cancer by Regulating Akt/GSK3beta/Beta-Catenin Signaling. Cell Physiol Biochem (2018) 49:1019-32. doi: 10.1159/000493286

66. Pei J, Song N, Wu L, Qi J, Xia S, Xu C, et al. TCF4/beta-catenin complex is directly upstream of FGF21 in mouse stomach cancer cells. Exp Ther Med (2018) 15:1041-7. doi: 10.3892/etm.2017.5493

67. Zhou L, Lu Y, Liu JS, Long SZ, Liu HL, Zhang J, et al. The role of miR-21/ RECK in the inhibition of osteosarcoma by curcumin. Mol Cell Probes (2020) 51:101534. doi: 10.1016/j.mcp.2020.101534

68. Pan Y, Sun Y, Liu Z, Zhang C. miR1925p upregulation mediates the suppression of curcumin in human NSCLC cell proliferation, migration and invasion by targeting $\mathrm{cMyc}$ and inactivating the Wnt/betacatenin signaling pathway. Mol Med Rep (2020) 22:1594-604. doi: 10.3892/ mmr.2020.11213

69. Dou H, Shen R, Tao J, Huang L, Shi H, Chen H, et al. Curcumin Suppresses the Colon Cancer Proliferation by Inhibiting Wnt/beta-Catenin Pathways via miR-130a. Front Pharmacol (2017) 8:877. doi: 10.3389/fphar.2017.00877

70. Wang J, Su Z, Lu S, Fu W, Liu Z, Jiang X, et al. LncRNA HOXA-AS2 and its molecular mechanisms in human cancer. Clin Chim Acta (2018) 485:22933. doi: 10.1016/j.cca.2018.07.004

71. Loewen G, Jayawickramarajah J, Zhuo Y, Shan B. Functions of lncRNA HOTAIR in lung cancer. J Hematol Oncol (2014) 7:90. doi: 10.1186/s13045014-0090-4

72. Jin SJ, Jin MZ, Xia BR, Jin WL. Long Non-coding RNA DANCR as an Emerging Therapeutic Target in Human Cancers. Front Oncol (2019) 9:1225. doi: 10.3389/fonc.2019.01225

73. Feng L, Shi L, Lu YF, Wang B, Tang T, Fu WM, et al. Linc-ROR Promotes Osteogenic Differentiation of Mesenchymal Stem Cells by Functioning as a Competing Endogenous RNA for miR-138 and miR-145. Mol Ther Nucleic Acids (2018) 11:345-53. doi: 10.1016/j.omtn.2018.03.004

74. Shao J, Shi CJ, Li Y, Zhang FW, Pan FF, Fu WM, et al. LincROR Mediates the Suppressive Effects of Curcumin on Hepatocellular Carcinoma Through Inactivating Wnt/beta-Catenin Signaling. Front Pharmacol (2020) 11:847. doi: 10.3389 /fphar.2020.00847

75. Liu T, Chi H, Chen J, Chen C, Huang Y, Xi H, et al. Curcumin suppresses proliferation and in vitro invasion of human prostate cancer stem cells by ceRNA effect of miR-145 and lncRNA-ROR. Gene (2017) 631:29-38. doi: 10.1016/j.gene.2017.08.008

76. Zhang P, Bai H, Liu G, Wang H, Chen F, Zhang B, et al. MicroRNA-33b, upregulated by EF24, a curcumin analog, suppresses the epithelial-tomesenchymal transition (EMT) and migratory potential of melanoma cells by targeting HMGA2. Toxicol Lett (2015) 234:151-61. doi: 10.1016/ j.toxlet.2015.02.018

77. Zhang S, Mo Q, Wang X. Oncological role of HMGA2 (Review). Int J Oncol (2019) 55:775-88. doi: 10.3892/ijo.2019.4856

78. Tan L, Wei X, Zheng L, Zeng J, Liu H, Yang S, et al. Amplified HMGA2 promotes cell growth by regulating Akt pathway in AML. J Cancer Res Clin Oncol (2016) 142:389-99. doi: 10.1007/s00432-015-2036-9

79. Malek A, Bakhidze E, Noske A, Sers C, Aigner A, Schafer R, et al. HMGA2 gene is a promising target for ovarian cancer silencing therapy. Int $J$ Cancer (2008) 123:348-56. doi: 10.1002/ijc.23491

80. Cai J, Sun H, Zheng B, Xie M, Xu C, Zhang G, et al. Curcumin attenuates lncRNA H19induced epithelialmesenchymal transition in\&nbsp; tamoxifenresistant breast cancer cells. Mol Med Rep (2021) 23:1. doi: $10.3892 / \mathrm{mmr} .2020 .11651$

81. Zhang W, Liu HT. MAPK signal pathways in the regulation of cell proliferation in mammalian cells. Cell Res (2002) 12:9-18. doi: 10.1038/ sj.cr.7290105

82. Guo YJ, Pan WW, Liu SB, Shen ZF, Xu Y, Hu LL. ERK/MAPK signalling pathway and tumorigenesis. Exp Ther Med (2020) 19:1997-2007. doi: $10.3892 /$ etm.2020.8454

83. Mirzaei H, Masoudifar A, Sahebkar A, Zare N, Sadri Nahand J, Rashidi B, et al. MicroRNA: A novel target of curcumin in cancer therapy. J Cell Physiol (2018) 233:3004-15. doi: 10.1002/jcp.26055 
84. Huang Y, Yuan K, Tang M, Yue J, Bao L, Wu S, et al. Melatonin inhibiting the survival of human gastric cancer cells under ER stress involving autophagy and Ras-Raf-MAPK signalling. J Cell Mol Med (2020) 25:148092. doi: $10.1111 / \mathrm{jcmm} .16237$

85. Li W, Yang W, Liu Y, Chen S, Chin S, Qi X, et al. MicroRNA-378 enhances inhibitory effect of curcumin on glioblastoma. Oncotarget (2017) 8:7393846. doi: 10.18632/oncotarget.17881

86. Zeng M, Zhu L, Li L, Kang C. miR-378 suppresses the proliferation, migration and invasion of colon cancer cells by inhibiting SDAD1. Cell Mol Biol Lett (2017) 22:12. doi: 10.1186/s11658-017-0041-5

87. Guo XB, Zhang XC, Chen P, Ma LM, Shen ZQ. miR378a3p inhibits cellular proliferation and migration in glioblastoma multiforme by targeting tetraspanin 17. Oncol Rep (2019) 42:1957-71. doi: 10.3892/or.2019.7283

88. Yu X, Zhong J, Yan L, Li J, Wang H, Wen Y, et al. Curcumin exerts antitumor effects in retinoblastoma cells by regulating the JNK and p38 MAPK pathways. Int J Mol Med (2016) 38:861-8. doi: 10.3892/ ijmm. 2016.2676

89. Zhu G, Shen Q, Jiang H, Ji O, Zhu L, Zhang L. Curcumin inhibited the growth and invasion of human monocytic leukaemia SHI-1 cells in vivo by altering MAPK and MMP signalling. Pharm Biol (2020) 58:25-34. doi: 10.1080/13880209.2019.1701042

90. Yao Q, Lin M, Wang Y, Lai Y, Hu J, Fu T, et al. Curcumin induces the apoptosis of A549 cells via oxidative stress and MAPK signaling pathways. Int J Mol Med (2015) 36:1118-26. doi: 10.3892/ijmm.2015.2327

91. Collett GP, Campbell FC. Curcumin induces c-jun N-terminal kinasedependent apoptosis in HCT116 human colon cancer cells. Carcinogenesis (2004) 25:2183-9. doi: 10.1093/carcin/bgh233

92. Khalid EB, Ayman EE, Rahman H, Abdelkarim G, Najda A. Natural products against cancer angiogenesis. Tumour Biol (2016) 37:14513-36. doi: 10.1007/s13277-016-5364-8

93. Awasthi M SS, Pandey VP, Dwivedi U. Curcumin: StructureActivity Relationship Towards its Role as a Versatile Multi-Targeted Therapeutics. Mini Rev Org Chem (2017) 14:311-22. doi: 10.2174/ 1570193X14666170518112446

94. Hua WF, Fu YS, Liao YJ, Xia WJ, Chen YC, Zeng YX, et al. Curcumin induces down-regulation of EZH2 expression through the MAPK pathway in MDA-MB-435 human breast cancer cells. Eur J Pharmacol (2010) 637:1621. doi: 10.1016/j.ejphar.2010.03.051

95. Toufektchan E, Toledo F. The Guardian of the Genome Revisited: p53 Downregulates Genes Required for Telomere Maintenance, DNA Repair, and Centromere Structure. Cancers (Basel) (2018) 10:135. doi: 10.3390/ cancers 10050135

96. Surget S, Khoury MP, Bourdon JC. Uncovering the role of p53 splice variants in human malignancy: a clinical perspective. Onco Targets Ther (2013) 7:5768. doi: 10.2147/OTT.S53876

97. Isobe M, Emanuel BS, Givol D, Oren M, Croce CM. Localization of gene for human p53 tumour antigen to band 17p13. Nature (1986) 320:84-5. doi: $10.1038 / 320084 \mathrm{a} 0$

98. Bourdon JC, Fernandes K, Murray-Zmijewski F, Liu G, Diot A, Xirodimas DP, et al. p53 isoforms can regulate p53 transcriptional activity. Genes Dev (2005) 19:2122-37. doi: 10.1101/gad.1339905

99. Li X, Xie W, Xie C, Huang C, Zhu J, Liang Z, et al. Curcumin modulates miR-19/PTEN/AKT/p53 axis to suppress bisphenol A-induced MCF-7 breast cancer cell proliferation. Phytother Res (2014) 28:1553-60. doi: $10.1002 /$ ptr.5167

100. Ye M, Zhang J, Zhang J, Miao Q, Yao L, Zhang J. Curcumin promotes apoptosis by activating the p53-miR-192-5p/215-XIAP pathway in nonsmall cell lung cancer. Cancer Lett (2015) 357:196-205. doi: 10.1016/ j.canlet.2014.11.028

101. Holcik M, Korneluk RG. Functional characterization of the X-linked inhibitor of apoptosis (XIAP) internal ribosome entry site element: role of La autoantigen in XIAP translation. Mol Cell Biol (2000) 20:4648-57. doi: $10.1128 / \mathrm{mcb} .20 .13 .4648-4657.2000$

102. Duckett CS, Li F, Wang Y, Tomaselli KJ, Thompson CB, Armstrong RC. Human IAP-like protein regulates programmed cell death downstream of Bcl-xL and cytochrome c. Mol Cell Biol (1998) 18:608-15. doi: 10.1128/ mcb.18.1.608
103. Xu R, Li H, Wu S, Qu J, Yuan H, Zhou Y, et al. MicroRNA-1246 regulates the radio-sensitizing effect of curcumin in bladder cancer cells via activating P53. Int Urol Nephrol (2019) 51:1771-9. doi: 10.1007/s11255-019-02210-5

104. Li H, Yu B, Li J, Su L, Yan M, Zhu Z, et al. Overexpression of IncRNA H19 enhances carcinogenesis and metastasis of gastric cancer. Oncotarget (2014) 5:2318-29. doi: 10.18632/oncotarget.1913

105. Yang F, Bi J, Xue X, Zheng L, Zhi K, Hua J, et al. Up-regulated long noncoding RNA H19 contributes to proliferation of gastric cancer cells. FEBS J (2012) 279:3159-65. doi: 10.1111/j.1742-4658.2012.08694.x

106. Liu G, Xiang T, Wu QF, Wang WX. Curcumin suppresses the proliferation of gastric cancer cells by downregulating H19. Oncol Lett (2016) 12:5156-62. doi: $10.3892 / o l .2016 .5354$

107. Xie C, Zhang LZ, Chen ZL, Zhong WJ, Fang JH, Zhu Y, et al. A hMTR4PDIA3P1-miR-125/124-TRAF6 Regulatory Axis and Its Function in NF kappa B Signaling and Chemoresistance. Hepatology (2020) 71:1660-77. doi: 10.1002/hep.30931

108. Meng Q, Liang C, Hua J, Zhang B, Liu J, Zhang Y, et al. A miR-146a-5p/ TRAF6/NF-kB p65 axis regulates pancreatic cancer chemoresistance: functional validation and clinical significance. Theranostics (2020) 10:3967-79. doi: 10.7150/thno.40566

109. Paciello F, Fetoni AR, Mezzogori D, Rolesi R, Di Pino A, Paludetti G, et al. The dual role of curcumin and ferulic acid in counteracting chemoresistance and cisplatin-induced ototoxicity. Sci Rep (2020) 10:1063. doi: 10.1038/ s41598-020-57965-0

110. Ghasemi F, Shafiee M, Banikazemi Z, Pourhanifeh MH, Khanbabaei H, Shamshirian A, et al. Curcumin inhibits NF-kB and Wnt/beta-catenin pathways in cervical cancer cells. Pathol Res Pract (2019) 215:152556. doi: 10.1016/j.prp.2019.152556

111. Marquardt JU, Gomez-Quiroz L, Arreguin Camacho LO, Pinna F, Lee YH, Kitade M, et al. Curcumin effectively inhibits oncogenic NF-kappaB signaling and restrains stemness features in liver cancer. J Hepatol (2015) 63:661-9. doi: 10.1016/j.jhep.2015.04.018

112. Li W, Sun L, Lei J, Wu Z, Ma Q, Wang Z. Curcumin inhibits pancreatic cancer cell invasion and EMT by interfering with tumorstromal crosstalk under hypoxic conditions via the IL6/ERK/NFkappaB axis. Oncol Rep (2020) 44:382-92. doi: 10.3892/or.2020.7600

113. Xiang L, He B, Liu Q, Hu D, Liao W, Li R, et al. Antitumor effects of curcumin on the proliferation, migration and apoptosis of human colorectal carcinoma HCT116 cells. Oncol Rep (2020) 44:1997-2008. doi: 10.3892/ or.2020.7765

114. Coker-Gurkan A, Bulut D, Genc R, Arisan ED, Obakan-Yerlikaya P, Palavan-Unsal N. Curcumin prevented human autocrine growth hormone (GH) signaling mediated NF-kappaB activation and miR-183-96-182 cluster stimulated epithelial mesenchymal transition in T47D breast cancer cells. Mol Biol Rep (2019) 46:355-69. doi: 10.1007/s11033-018-4479-y

115. Kang HJ, Lee SH, Price JE, Kim LS. Curcumin suppresses the paclitaxelinduced nuclear factor-kappaB in breast cancer cells and potentiates the growth inhibitory effect of paclitaxel in a breast cancer nude mice model. Breast J (2009) 15:223-9. doi: 10.1111/j.1524-4741.2009.00709.x

116. Anand P, Sundaram C, Jhurani S, Kunnumakkara AB, Aggarwal BB. Curcumin and cancer: an "old-age" disease with an "age-old" solution. Cancer Lett (2008) 267:133-64. doi: 10.1016/j.canlet.2008.03.025

117. Ferri C WK, Otero K, Kim YH. Effectiveness of curcumin for treating cancer during chemotherapy. Altern Complement Ther (2018) 24:13-8. doi: 10.1089/act.2017.29147.yhk

118. Abbas MN, Kausar S, Cui H. Therapeutic potential of natural products in glioblastoma treatment: targeting key glioblastoma signaling pathways and epigenetic alterations. Clin Transl Oncol (2020) 22:963-77. doi: 10.1007/ s12094-019-02227-3

119. Xiang Y, Guo Z, Zhu P, Chen J, Huang Y. Traditional Chinese medicine as a cancer treatment: Modern perspectives of ancient but advanced science. Cancer Med (2019) 8:1958-75. doi: 10.1002/cam4.2108

120. Asadi S, Gholami MS, Siassi F, Qorbani M, Sotoudeh G. Beneficial effects of nano-curcumin supplement on depression and anxiety in diabetic patients with peripheral neuropathy: A randomized, double-blind, placebocontrolled clinical trial. Phytother Res (2020) 34:896-903. doi: 10.1002/ ptr.6571 
121. Hassaniazad M, Inchehsablagh BR, Kamali H, Tousi A, Eftekhar E, Jaafari MR, et al. The clinical effect of Nano micelles containing curcumin as a therapeutic supplement in patients with COVID-19 and the immune responses balance changes following treatment: A structured summary of a study protocol for a randomised controlled trial. Trials (2020) 21:876. doi: 10.1186/s13063-020-04824-y

122. Heshmati J, Golab F, Morvaridzadeh M, Potter E, Akbari-Fakhrabadi M, Farsi F, et al. The effects of curcumin supplementation on oxidative stress, Sirtuin-1 and peroxisome proliferator activated receptor gamma coactivator 1alpha gene expression in polycystic ovarian syndrome (PCOS) patients: A randomized placebo-controlled clinical trial. Diabetes Metab Syndr (2020) 14:77-82. doi: 10.1016/j.dsx.2020.01.002

123. Saghatelyan T, Tananyan A, Janoyan N, Tadevosyan A, Petrosyan H, Hovhannisyan A, et al. Efficacy and safety of curcumin in combination with paclitaxel in patients with advanced, metastatic breast cancer: A comparative, randomized, double-blind, placebo-controlled clinical trial. Phytomedicine (2020) 70:153218. doi: 10.1016/j.phymed.2020.153218

Conflict of Interest: The authors declare that the research was conducted in the absence of any commercial or financial relationships that could be construed as a potential conflict of interest.

Copyright (c) 2021 Wang, Zhang, Liu, Yang, Tian, Yang, Li, Shao, Su and Song. This is an open-access article distributed under the terms of the Creative Commons Attribution License (CC BY). The use, distribution or reproduction in other forums is permitted, provided the original author(s) and the copyright owner(s) are credited and that the original publication in this journal is cited, in accordance with accepted academic practice. No use, distribution or reproduction is permitted which does not comply with these terms. 